\title{
Tuberculosis of the conjunctiva occurring in association with a neighbouring lupus vulgaris lesion
}

\author{
C D Cook, M Hainsworth
}

\begin{abstract}
A case of tuberculosis of the conjunctiva in association with a neighbouring lupus vulgaris lesion is reported. Both lesions resolved within one month of starting antituberculous therapy. Tuberculosis of the conjunctiva is nowadays a rare condition. It should be considered in the differential diagnosis of any unusual chronic conjunctivitis, particularly in patients who are at risk of contracting tuberculosis.
\end{abstract}

Tuberculosis of the conjunctiva is a rare condition. The first case was reported by Koester in 1873.' Eyre reviewed 206 cases which had been reported over a 30-year period from 1882 to 1912 , with a further personal series of 24 cases. ${ }^{2}$ Lundsgaard reported 48 cases in 1915 and Igeisheimer another 22 cases in 1922. ${ }^{1}$ There have been subsequent isolated reports..$^{3-16}$

\section{Case report}

A 25-year-old Zulu woman was referred with a six-month history of conjunctivitis of the left eye associated with an ulcer adjacent to the left nares. She had no other complaints and had previously been well. She had been treated with chloramphenicol ointment for three weeks, with no improvement.

On examination the visual acuity in the righ eye was $6 / 6$ and in the left eye was $6 / 12$. The right eye was normal. There was a left-sided conjunctivitis with a mucopurulent discharge, with superficial ulceration of the lower lid margin, obliteration of the punctum, and cicatricial entropion of the lid (Fig 1). The lower third of the cornea showed mild superficial stromal scarring,

Edendale Hospital, Pietermaritzburg, Republic of South Africa C D Cook

M Hainsworth

Correspondence to: C D Cook FCS (Ophth) SA Edendale Hospital, P Bag X9020, Pietermaritzburg

3200 , Natal, Republic of South Africa.

Accepted for publication

8 December 1989

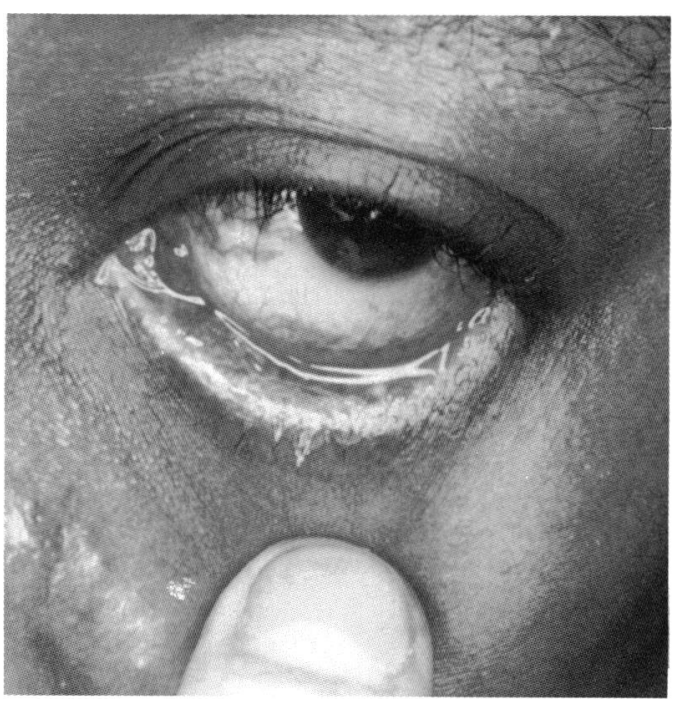

Figure 1: Left sided chronic conjunctivitis with ulceration of the lid margin.

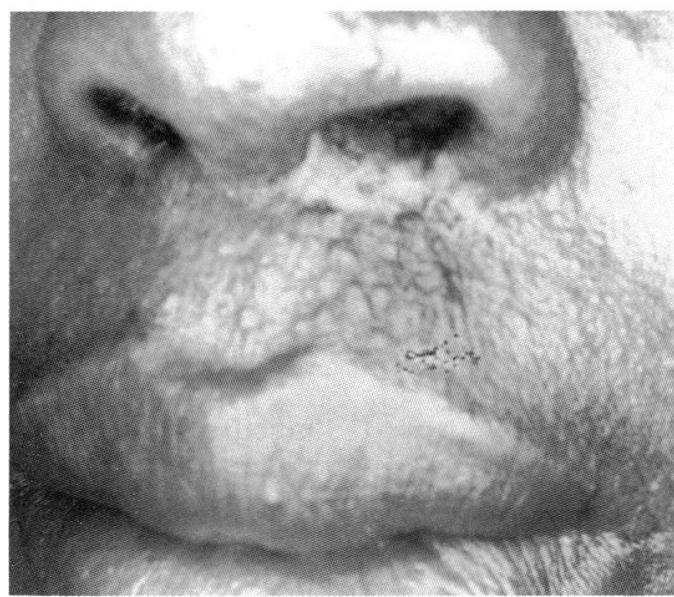

Figure 2: Lupus vulgaris lesion adjacent to the left nares.

with a Hudson-Stahli ferritin line. The eye was otherwise normal. There was no palpable preauricular or other regional lymphadenopathy. There was a chronic superficial ulcer of the skin under the left nares (Fig 2). The nose and throat were normal. The skin lesion was thought most likely to be lupus vulgaris, and a provisional diagnosis of primary tuberculous lupus vulgaris with an associated tuberculous conjunctivitis was made.

The conjunctival swab yielded Staphylococcus aureus on culture, sensitive to chloramphenicol. No acid-fast bacilli were seen on microscopy. Treatment with chloramphenicol ointment was given for one week, with no improvement. The Mantoux test was strongly positive. The chest $x$ ray was normal. Biopsy specimens were taken from the skin lesion and the conjunctiva. Histology of the skin lesion showed appearances consistent with lupus vulgaris, with tuberculoid granulomata being present in the papillary dermis (Figs 3A, B). Histology of the con-

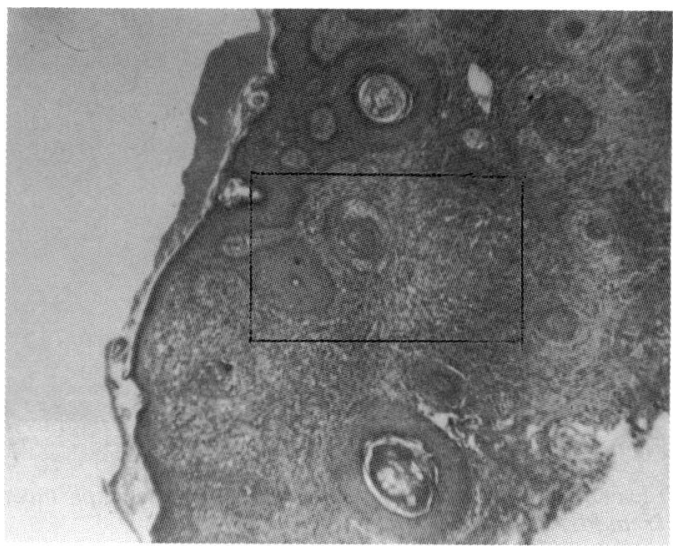

Figure 3A: $\times 20$.

Figure 3: Histology of the skin lesion, showing a tuberculoid granuloma. ( $H$ and $E$.) 


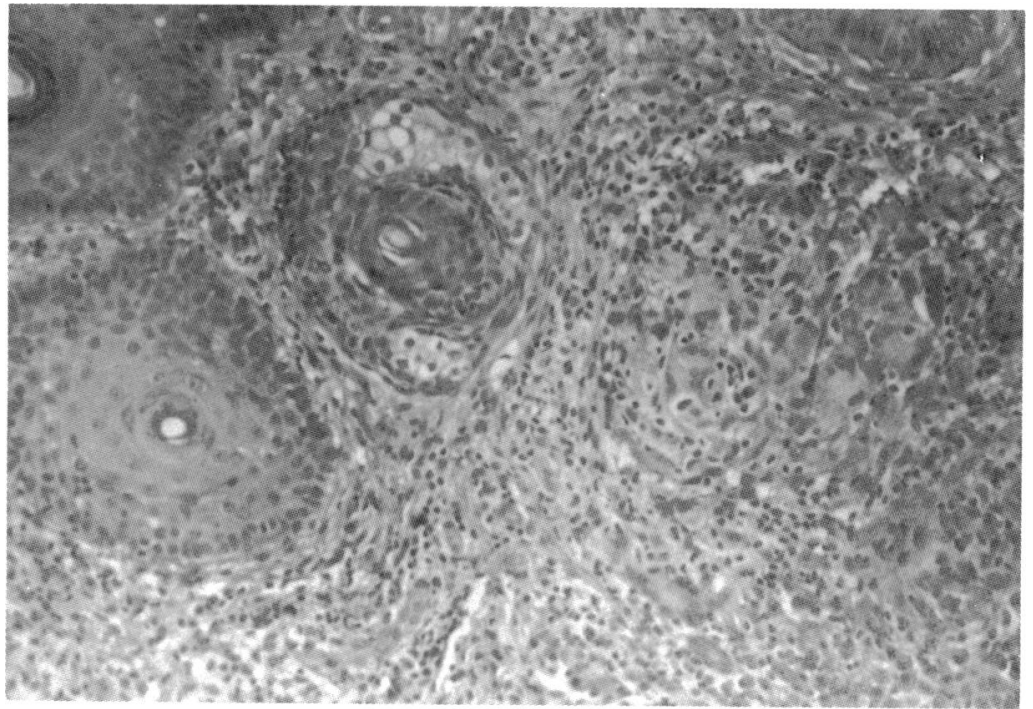

Figure $3 B: \times 85$.

junctiva showed appearances consistent with tuberculous conjunctivitis, with tuberculoid granulomata being present (Figs 4A, B). No acid-fast bacilli were seen on histological examination.

The patient was treated with a standard anti-

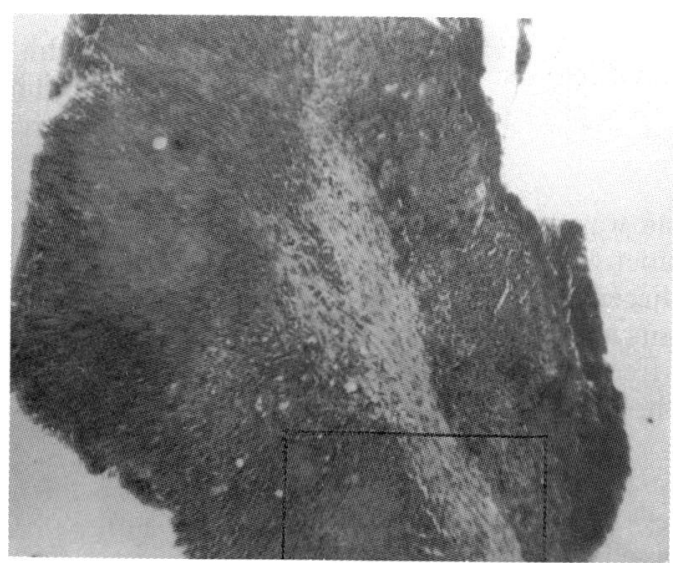

Figure $4 A: \times 20$.

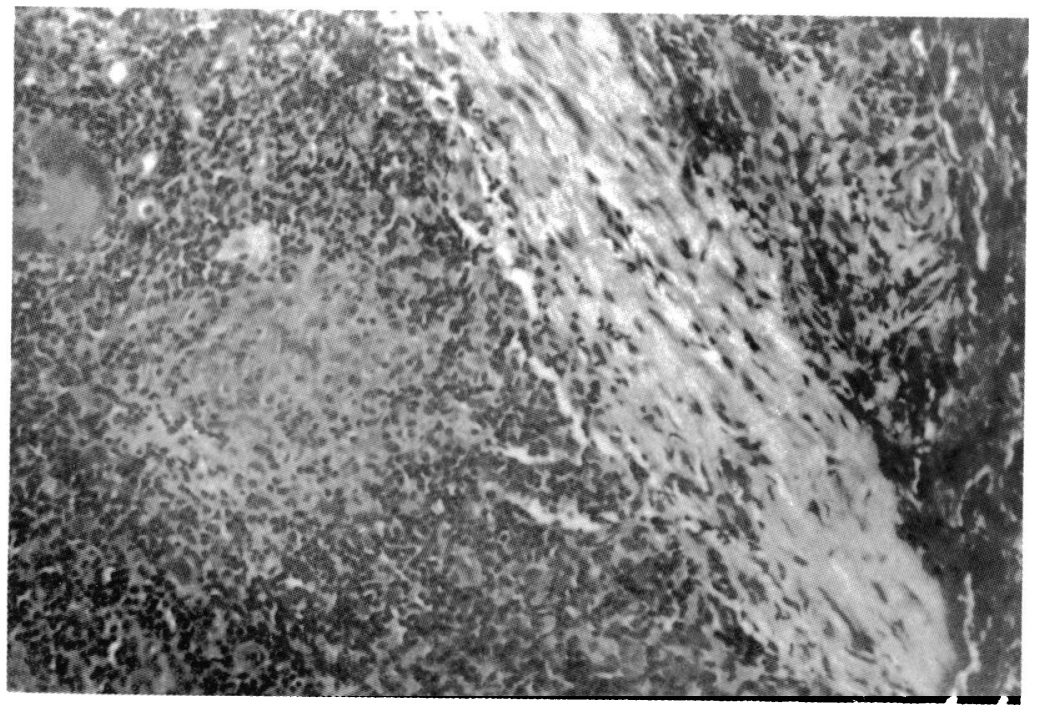

Figure $4 B: \times 85$.

Figure 4: Histology of the conjunctiva, showing multiple tuberculoid granulomata. (H and E.) $32 \times$. Inset $100 \times$. tuberculous regimen of rifampicin $450 \mathrm{mg}$ daily, isoniazid $400 \mathrm{mg}$ daily, and pyrazinamide $1.5 \mathrm{~g}$ daily for six months. The skin lesion and conjunctivitis resolved on this treatment after one month.

\section{Discussion}

Primary tuberculous conjunctivitis occurs as a result of an exogenous infection. There are five clinical types - ulcerative, nodular, hypertrophic, granulomatous, and pedunculated. It may occur more commonly in young than old patients, and may be associated with regional lymphadenopathy. It runs a chronic course, and may heal with scarring or may spread to involve adjacent tissues and structures.

Secondary tuberculous conjunctivitis occurs as a result of spread of infection from a contiguous focus. There are six clinical types ulcerative, nodular, hypertrophic, granulomatous, pedunculated, and lupoid. It may occur more commonly in adults than children and may not be associated with regional lymphadenopathy.'

In both instances, the diagnosis is confirmed on histological examination. Treatment is with systemic antituberculous therapy, and there is usually rapid resolution of the conjunctivitis on this therapy.

Our patient showed features of a conjunctivitis occurring in association with a neighbouring, but not contiguous, lupus vulgaris lesion. While the diagnosis of tuberculosis was sug gested in our patient by the lupus vulgaris skin lesion, the clinical picture of tuberculous conjunctivitis may be sufficiently varied as to make a clinical diagnosis difficult. It is therefore necessary to consider it in any unusual chronic conjunctivitis, with or without regional lymphadenopathy, particularly in patients living in communities where the incidence of tuberculosis is still high.

1 Woods AC. Ocular tuberculosis. In: Sorsby A, ed. Modern Ophthalmology. 2nd ed. London: Butterworths, 1972; 2 $105-15$

2 Eyre JWH. Tuberculosis of the conjunctiva - its aetiology, pathology, and diagnosis. Lancet 1912; i: 1319-28.

3 Goldfarb AA, Seltzer I. Primary tuberculosis of the conjunctiva. Am J Dis Child 1946; 72: 211-5.

4 Bruce GM, Locatcher-Khorazo D. Primary tuberculosis of the conjunctiva. Arch Ophthalmol 1947; 37: 375-8.

5 Kamel S. Primary tuberculosis of the conjunctiva $B$ f Ophthalmol 1950; 34: 322-7.

6 Donegan JM. Primary tuberculosis of the conjunctiva. $A m \mathcal{F}$ Ophthalmol 1950; 33: 1117-21.

7 Sykowski P. Streptomycin treatment of conjunctival tuberculosis. Am f Ophthalmol 1950; 33: 1291-2.

8 Eadie S. Primary tuberculosis of the conjunctiva treated with streptomycin and PAS. BrF Ophthalmol 1954; 38: 568-70.

9 Kamel S. Tuberculosis of the conjunctiva. Bull Ophthal Soc Egypt 1955; 48: 91-7.

10 Anhault EF, Zavell S, Chang G, Byron HM. Conjunctival tuberculosis. Am F Ophthalmol 1960; 50: 265-6.

11 Chandler AC, Locatcher-Khorazo D. Primary tuberculosis of the conjunctiva. Arch Ophthalmol 1964; 71: 202-5.

12 Sollom AW. Primary conjunctival tuberculosis. $\mathrm{Br} f \mathrm{Oph}$ thalmol 1967; 51: 685-6.

13 Archer D, Bird A. Primary tuberculosis of conjunctiva. $\mathrm{Br}$ f Ophthalmol 1967; 51: 679-84.

14 Whitford J, Hansman D. Primary tuberculosis of the con junctiva. Med f Aust 1977; i: 486-7.

15 Charles V, Charles SX. Primary tuberculosis of conjunctiva. F Ind Med Assoc 1980; 74: 74-5.

16 Lamba PP. Conjunctival tuberculosis of endogenous origin 31: 89-92. 